\title{
Comércio Internacional, Agricultura e Meio Ambiente: teorias, evidências e controvérsias empíricas
}

\author{
Rodrigo Daniel Feix ${ }^{1}$ \\ Silvia Helena Galvão de Miranda ${ }^{2}$ \\ Geraldo Sant'Ana de Camargo Barros ${ }^{3}$
}

\begin{abstract}
Resumo: Este artigo constitui uma revisão das principais questões teóricas e empíricas atinentes às interfaces econômicas entre agricultura, meio ambiente e comércio, em geral, e para o Brasil em particular. Ao longo dos anos, diante da multiplicidade de resultados desencontrados observados na literatura, tornou-se cada vez mais claro o papel desempenhado pelas especificidades setoriais e regionais nesse campo de estudo. A tendência ao emprego de métodos e processos produtivos com elevado potencial degradante ao meio ambiente, observada em segmentos importantes da agricultura brasileira, além de gerar desdobramentos internos pouco desprezíveis, contribui para situar o País na alça de mira de movimentos ambientalistas internacionais. Ainda, dificulta a inserção de seus produtos no mercado internacional, cada vez mais reflexo das questões ambientais globais. Conclui-se pela necessidade de definição de políticas ambientais sinérgicas, capazes de dotar a agricultura brasileira de padrões mais sustentáveis de produção, sem comprometer sua competitividade.
\end{abstract}

Palavras-chave: comércio, ambiente, agricultura, relações Norte-Sul.

Abstract: This article provides a review of the major theoretical and empirical issues related to the economic interfaces between agriculture, environment and trade, in general, and particularly to Brazil. Over the years, given the multiplicity of controversial results registered in the literature, it became increasingly clear the role played by the sector and regional specificities in this field of study. The trend of adopting processes and methods potentially and highly degrading to environment, noticed in important segments of Brazilian agriculture, besides generating domestic effects rather negligible, contributes

\footnotetext{
1 E-mail: feix@usp.br

2 E-mail: smiranda@esalq.usp.br

3 E-mail: gscbarro@esalq.usp.br
} 
to place the country on the handle of sight of the international environmental groups. Moreover, it hampers the acceptance of national goods in the international market, increasingly reflecting the global environmental issues. Conclusively, it is necessary to define synergistic environmental policies, capable of providing more sustainable patterns of production to the Brazilian agriculture, without compromising their competitiveness.

Key-words: trade, environment, agriculture, North-South relations.

Classificação JEL: Q000, Q340, Q560, F180.

\section{Introdução}

Nas últimas décadas, o setor externo, gradativamente, ampliou sua importância para a elevação dos níveis de atividade econômica e melhoria dos indicadores de emprego e renda dos países. Entretanto, a intensificação da iniquidade social e da degradação dos recursos naturais, observada nesse mesmo período, vem sendo interpretada como reação sintomática dos limites físicos e morais do tradicional modelo de desenvolvimento capitalista, no qual se assenta a atual onda liberalizante (HAWKEN, LOVINS e LOVINS, 1999).

Já a partir da década de 1970, os esforços visando à formulação de um modelo de desenvolvimento que crie efeitos sinérgicos entre comércio internacional, sustentabilidade ambiental e justiça social romperam os limites do círculo acadêmico e entraram na pauta de discussão dos principais organismos internacionais de desenvolvimento econômico, dos Estados nacionais e da sociedade civil em geral.

Na esteira desse processo, as legislações ambientais nacionais gradativamente estão se tornando mais rigorosas e proliferam-se normas e regulamentações ambientais objetivando estabelecer padrões ecologicamente sustentáveis de gestão, produção, transporte, comercialização e descarte dos bens. A primazia dos estudos versando sobre os vínculos entre o comércio internacional e o meio ambiente é tradicionalmente creditada aos trabalhos de Baumol (1971), Magee e Ford (1972) e Walter (1973).

Reportando-se aos numerosos estudos conduzidos ao longo das três últimas décadas, a fim de se apurar os possíveis vínculos econômicos entre comércio e meio ambiente e, assim, construir um referencial teórico sobre o tema, pode-se identificar a recorrência de sete indagações principais ou tópicos norteadores da agenda de pesquisa:

i) De que forma essas políticas ambientais determinam os padrões de comércio e as vantagens comparativas?

ii) Como as políticas ambientais afetam os termos de troca?

iii) Quais os reflexos dessas políticas sobre os padrões de produção e consumo? 
iv) O comércio resulta em degradação ambiental?

v) As políticas ambientais são um determinante da direção dada ao fluxo de investimento direto externo (IDE)?

vi) Como as políticas ambientais afetam o retorno dos fatores de produção?

vii) Qual o papel desempenhado pelo comércio nas questões ambientais globais?

Parte das respostas a essas indagações ainda carece de satisfatória robustez teórica e empírica. Diante da multiplicidade de resultados desencontrados, tornou-se cada vez mais claro o papel das especificidades setoriais e regionais nesse campo de estudo.

O setor do agronegócio, por exemplo, que, segundo dados publicados pelo Cepea/CNA (2008), em 2005, respondeu por cerca de 30\% do PIB brasileiro, é analisado apenas marginalmente pela literatura sobre comércio-meio ambiente. Diante disso e das particularidades da economia brasileira, este trabalho tem por objetivo central contextualizar as principais discussões e avanços teóricos, metodológicos e empíricos acerca da interação comércio-meio ambiente no setor.

Optou-se, ainda, por abordar de forma integrada os cinco primeiros tópicos que, segundo estudo do International Institute for Sustainable Development (IISD, 2004), constituem o foco principal da atual agenda de pesquisas, dando especial destaque à importância da problemática ambiental no setor agrícola.

Assim, o trabalho foi estruturado de modo a facilitar a identificação das relações de causa-efeito entre o comércio e o meio ambiente, dividindo-se em cinco seções, além desta introdução. A seção 2 trata dos impactos ambientais do comércio internacional, seguida por uma discussão sobre os efeitos da regulação ambiental sobre esse comércio. A seção 4 busca identificar as políticas ambientais no âmbito da competitividade do setor agrícola. Na sequência, caracterizase o setor agroexportador e sua inter-relação com o ambiente, e, finalmente, apresentam-se algumas considerações finais.

\section{Impactos ambientais do comércio internacional}

O principal trunfo teórico dos defensores do livre comércio, aceito até o limiar da década de 1990, era que a redução das barreiras comerciais resultaria inevitavelmente em ganhos de bem-estar para todos os participantes. Como até aquele período a questão ambiental não passava de coadjuvante na agenda econômica internacional, os modelos empregados para gerar estimativas de variações de bem-estar associadas ao processo de liberalização comercial raramente incorporavam o ambiente em suas análises. A partir de então, face à série de previsões ambientais catastróficas e à necessidade de repensar as fontes de energia tradicionalmente empregadas na atividade econômica, os argumentos favoráveis ao livre comércio passaram a ser questionados em várias frentes. 
O debate acerca do impacto do comércio internacional sobre o meio ambiente surge essencialmente a partir de sua interligação com o crescimento econômico. Em razão de o meio ambiente ser fonte de insumos básicos para a produção e destino comum dos rejeitos da atividade econômica, o aumento no nível global de produção tende a gerar, em contrapartida, maior pressão sobre os recursos naturais.

A inserção do comércio internacional nesse processo ocorre por diversos meios e está comumente associada à especialização produtiva que emana. É sabido que o estabelecimento de um ambiente institucional favorável à livre circulação de bens e serviços por longos períodos, tal qual o observado nos últimos 50 anos, atua como um vetor de estímulo à especialização produtiva dos países em setores de maiores vantagens comparativas, favorece a alocação eficiente dos recursos e, ceteris paribus, gera como resultado o crescimento da riqueza mundial. Não obstante, segundo Almeida (2002), o efeito líquido da expansão da riqueza sobre o meio ambiente pode adquirir múltiplas formas e é conhecido como efeito escala comércio-meio ambiente.

$\mathrm{O}$ resultado do efeito escala comércio-meio ambiente, analisado em sua totalidade, pode ser positivo ou negativo. Positivo porque o aumento da eficiência na alocação dos recursos e a intensificação da concorrência (ambos induzidos pela liberalização comercial) reduzem a demanda sobre os recursos naturais e minimizam os desperdícios ao longo do ciclo produtivo. Vale destacar aqui que, segundo a Curva Ambiental de Kuznets (EKC - do inglês Environmental Kuznets Curve), há uma correlação negativa entre os níveis de riqueza e degradação ambiental, o que corrobora os argumentos dos defensores do livre comércio. ${ }^{4}$

Por outro lado, segundo o modelo keynesiano de determinação da renda, o consumo agregado é função direta do nível de renda corrente da economia. Isso significa que um aumento na renda global, ao expandir o conjunto de possibilidades de consumo, também eleva o nível de demanda agregada na economia. Consequentemente, os agentes econômicos são estimulados a aumentarem os níveis de produção, acelerando a demanda sobre os recursos naturais. Esse ciclo atuaria de forma perniciosa ao ambiente, já que produz tanto externalidades de consumo quanto externalidades de produção. Percebe-se então que, dependendo do setor produtivo e das políticas ambientais vigentes, os efeitos negativos podem compensar os positivos.

Conforme demonstra estudo conduzido pelo International Institute for Sustainable Development (IISD, 2001), além do efeito escala, existem ainda outros vínculos, de maior complexidade de identificação causal, entre a abertura comercial e o emprego dos recursos naturais. Trata-se dos efeitos composição e tecnológico.

\footnotetext{
4 Os estudos de Bhagwati (1993), Grossman e Krueger (1993) e Dean (1999) confirmam essa hipótese.
} 
O efeito composição relaciona mudanças no padrão de especialização produtiva dos países em função da abertura econômica. O resultado dessa relação pode agravar ou amenizar o impacto da produção e consumo internos sobre o meio ambiente, dependendo, dentre outros fatores, do rigor da legislação ambiental nacional.

Atualmente, mensurar a ocorrência do efeito composição é uma preocupação premente da comunidade ambiental nos Países Desenvolvidos (PDs), principalmente na União Européia, pela possibilidade de países com regulamentações ambientais mais brandas se especializarem em setores com alto potencial poluidor, visando minimizar os custos de produção e ganhar competitividade. Outra argumentação comum é a que relaciona as legislações ambientais menos rigorosas dos Países em Desenvolvimento (PEDs) aos fluxos de Investimento Direto Externo (IDE).

Não obstante, os estudos voltados a identificar um trade-off entre rigor das regulamentações ambientais e fluxo de IDE de alto potencial degradante ambiental não foram capazes de oferecer evidências empíricas suficientes sobre o tema. Isso porque a decisão de localização espacial de uma empresa envolve, além dos custos ambientais, outros fatores, tais como custo e produtividade da mão de obra, acesso aos insumos, mercado consumidor, risco político, etc. Segundo o estudo do IISD (2001), os custos de controle ambiental representam, em média, de $2 \%$ a $3 \%$ dos custos totais da indústria e, portanto, atuariam como vetor secundário na definição do fluxo de IDE.

Quanto ao efeito tecnológico, este aborda a possibilidade de haver uma correlação entre liberalização comercial e mudanças nos modos de produção domésticos, segundo a tecnologia utilizada. O efeito tecnológico depende da forma como a liberalização comercial influi sobre a transferência de tecnologia e os processos produtivos dos produtos comercializados. O efeito é positivo para o meio ambiente quando se reduz o nível de poluição por unidade produtiva.

Os novos mercados que se abrem podem gerar rendas e investimentos que permitam às empresas acelerar a rentabilidade do capital e o investimento em plantas produtivas com processos mais limpos e eficientes (PORTER, 1991). Contudo, de acordo com Dua e Esty (1997), o acirramento da concorrência externa, ao mesmo tempo em que pode levar a inovações tecnológicas, também pode induzir as empresas a adotarem uma estratégia de forte racionalização de custos, cortando até os gastos com melhorias ambientais (estratégia race to the bottom).

As teorias discutidas anteriormente continuam a ser estudadas e testadas por um número crescente de autores. Grossman e Krueger (1993), em sua avaliação do Nafta sobre a temática ambiental; Hettige, Lucas e Wheeler (1992), que identificaram que países com taxas de crescimento do PIB mais altas possuem taxas menores de aumento de intensidade tóxica; e Anderson (1992), que mostra que a redução das barreiras comerciais impostas aos produtos das indústrias de 
alimentos e carvão vegetal provavelmente resultaria em diminuição da poluição global.

Birdsall e Wheeler (1993) tentaram determinar se o nível de abertura está ou não associado ao desenvolvimento de indústrias intensivas em poluição nos países da América Latina, observando que, com a liberalização comercial, os padrões ambientais mais elevados dos países industrializados são transferidos para os PEDs.

Mais recentemente, Dean (1999) desenvolveu um modelo de equações simultâneas que incorpora as interações estáticas e dinâmicas entre comércio e meio ambiente. Estimativas desse modelo, geradas a partir de dados chineses sobre a poluição da água, mostram que, de fato, a liberalização comercial se relaciona direta e indiretamente com o crescimento das emissões e que esses efeitos são de sinais opostos.

Nem todos os autores compartilham o mesmo ponto de vista. Um estudo teórico realizado por Copeland e Taylor (1994) analisou os efeitos escala, composição e tecnológico do comércio internacional sobre a poluição em um modelo Norte-Sul e demonstrou que o livre comércio diminui os níveis de poluição no Norte, mas aumenta os níveis de poluição no Sul e globalmente. O estudo de Chilchilnisky (1994) identifica o impacto da maior liberdade comercial sobre o uso dos recursos naturais quando os países ainda carecem definir claramente os direitos de propriedade.

Daly (1993), Esty (1994) e Esty e Geradin (1997) afirmam que, em consequência da liberalização comercial, os países são provavelmente levados a competir entre si, relaxando os padrões domésticos de qualidade ambiental a fim de aumentar (ou resguardar) sua competitividade, ou mesmo desencorajar a ratificação de políticas ambientais de modo geral. Outros autores, como Barrett (1994), Kennedy (1994) e Rauscher (1994), mostram que o dumping ecológico ${ }^{5}$ pode ocorrer por razões estratégicas. Esty e Geradin (1997) afirmam que os grupos industriais e trabalhistas vinculam os ambientalistas a seu temor quanto à possibilidade de a integração econômica criar portos de poluição (pollution havens) com regulações ambientais de baixa exigência e alta competitividade. Esse sentimento tem promovido a busca pela harmonização das políticas ambientais nas áreas de livre comércio, como a União Européia , o Nafta e o Mercosul (GUTIERREZ, 1997).

Essas reivindicações carecem de suporte empírico. O único trabalho encontrado na literatura versando sobre o tema é o de Eliste e Fredriksson (1998), que consideram o impacto da liberalização comercial e a estratégia de comportamento dos países exportadores na determinação das regulações ambientais. Em estudo empírico sobre o setor agrícola, os autores não encontraram qualquer evidência

5 Obtenção de menores custos de produção em função do menor rigor dos regimes de políticas ambientais nacionais (Almeida, 1997). 
de estratégia "race to the bottom". Esse resultado muito provavelmente se deve a aspectos específicos do setor.

Uma coletânea de trabalhos que são construtivamente críticos aos ganhos do comércio sob a perspectiva ambiental foi editada por Ekins, Folke e Costanza (1994). Seus argumentos de maior importância destacam que: i) a riqueza adicional gerada a partir do crescimento econômico resultante da liberalização comercial não é destinada à proteção ambiental; ii) mesmo se for dirigida à proteção ambiental, nada pode ser feito a respeito dos danos não reparáveis ao meio ambiente associados ao crescimento econômico; e iii) o aumento na massa de transporte necessária para o comércio contribui substancialmente para os danos ambientais relacionados ao uso de energia.

Uma observação comum é que os PEDs estão se especializando em indústrias "sujas" (HETTIGE, LUCAS e WHEELER, 1992; LOW e YEATS, 1992). Segundo Lee e Roland-Holst (1993), as exportações dos PEDs estão concentradas em produtos relativamente intensivos em poluição, enquanto as exportações dos PDs são basicamente de produtos "limpos". O desmatamento na região amazônica no Brasil e a degradação dos recursos naturais de países asiáticos, realizados a partir de atividades orientadas ao abastecimento do mercado internacional, estão entre os principais exemplos citados.

Em síntese, pode-se dizer que os vínculos entre a liberalização comercial e o meio ambiente são bastante complexos. A literatura sobre o tema indica que, de forma geral, espera-se que a liberalização comercial afete negativamente o ambiente no curto prazo e que indústrias intensivas em poluição se expandam mais nos PEDs. A partir desses resultados, muitos pesquisadores defendem que políticas de liberalização comercial dissociadas de provisões ambientais não são benéficas a todos os países.

\section{Impactos comerciais da regulação ambiental}

Para se compreender as consequências diretas e indiretas que um modelo de desenvolvimento construído sob a perspectiva da sustentabilidade ambiental produz ou poderá vir a produzir sobre os fluxos de comércio mundial e a competitividade dos países, é indispensável o conhecimento dos princípios e instrumentos de política ambiental adotados, assim como suas interfaces comerciais.

Segundo trabalho do Department for Environment, Food and Rural Affairs do Reino Unido (DEFRA, 2007), o debate teve início nos Estados Unidos, em meados da década de 1960, quando, atendendo à demanda de diversos segmentos da sociedade, foi formada a Agência de Proteção Ambiental (EPA - do inglês Environmental Protection Agency) e assinado o Clean Air Act. As múltiplas formas das regulamentações ambientais implantadas promoveram um amplo debate acerca de seus efeitos econômicos. Como resultado, já no início da década de 
1990, havia se formado a base teórica sobre os reflexos econômicos domésticos gerados pela regulação ambiental.

Os primeiros estudos realizados, conduzidos por economistas de origem neoclássica, destacadamente por Baumol e Oates (1975), Pethig (1976) e Siebert (1977), concluíram que as novas regulações ambientais impactaram significativamente sobre os custos de produção e a competitividade dos Estados Unidos. Segundo esses autores, haveria um trade-off entre rigor da regulação ambiental e competitividade.

Por mais de uma década o foco das análises foi medir esse trade-off, até que Porter (1991) e Porter e van der Linde (1995a) inauguraram uma nova abordagem, chegando a conclusões flagrantemente opostas às conhecidas até então. Demonstraram ser possível atingir a proteção ambiental simultaneamente à manutenção, ou até mesmo aumento, da competitividade.

Almeida (2002) sintetizou a polarização do debate entre os defensores da visão tradicional (trade-off ou neoclássica) versus a abordagem revisionista recente. $\mathrm{Na}$ primeira, há um conflito inevitável entre ganhos ambientais e os econômicos, derivado do conceito de externalidade negativa. Dado que o agente microeconômico maximiza lucros pela alternativa de custo mínimo de produção, cuja escolha não considera os danos ambientais, as regulações que visam justamente induzi-lo a "internalizar" as externalidades ambientais, acarretam-lhe necessariamente um acréscimo de custo.

Por outro lado, na abordagem revisionista recente, conhecida como a "hipótese de Porter", enfatizam-se os efeitos sinérgicos entre regulações ambientais e competitividade. Segundo tal visão, não existe um conflito inevitável entre ganhos econômicos e ambientais. Ao promoverem melhorias ambientais, as empresas podem economizar insumos, racionalizar o processo produtivo, aproveitar resíduos, diferenciar o produto final e, com isso, ganhar em competitividade. Dessa forma, a adequação a regulações ambientais mais exigentes não se constituiria num jogo de soma zero, pois poderia representar uma nova fonte de permanente mudança estrutural. Contudo, não é qualquer tipo de regulamentação que levará a esse tipo de solução (ALMEIDA, 2002). ${ }^{6}$

Com o estabelecimento de dois campos de estudo radicalmente opostos, Jaffe et al. (1995) ingressaram no debate para ocupar um espaço intermediário, afirmando que "a verdade a respeito da relação entre proteção ambiental e competitividade repousa entre os dois extremos da corrente discussão". A partir de então, surgiriam diferentes vertentes de exploração, buscando identificar as circunstâncias em que as regulações podem impactar favorável ou adversamente a economia.

Segundo o Defra (2007), as regulações ambientais podem impactar na competitividade por meio dos mecanismos descritos no modelo estilizado

\footnotetext{
6 Os princípios das boas regulamentações estão em Porter e van der Linde (1995b).
} 
do Quadro 1. A natureza da influência será determinada em parte pela atual eficiência das empresas no emprego de energia, pelo seu poder de mercado (até que ponto é possível transferir ao consumidor o aumento nos custos associados à regulação) e pela sua capacidade de resposta através de mudanças tecnológicas.

A um nível maior de agregação, o saldo dos efeitos em termos de padrões intersetoriais de produto e produtividade pode ser influenciado pelo grau em que uma economia é intensiva na utilização dos recursos ou fatores que são objeto da regulação (intensidade energética) e na medida em que ela é dotada desses recursos (vantagens comparativas).

O Quadro 1 (coluna central) indica, ainda, como esses diferentes níveis de ajuste serão revelados em termos da competitividade da economia em questão, relativamente aos seus concorrentes. Os efeitos líquidos serão percebidos na renda relativa da economia e no crescimento da produtividade, em mudanças nas suas vantagens comparativas e desempenho comercial, nos padrões do fluxo de IDE, entre outros.

Quadro 1. Efeitos das regulamentações ambientais sobre a competitividade.

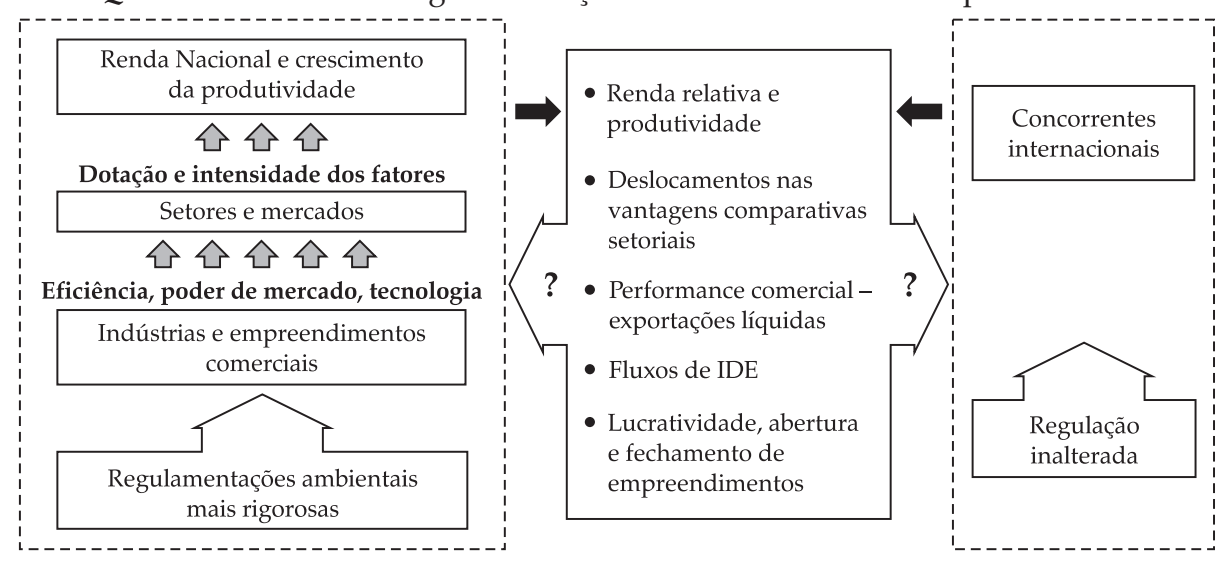

Fonte: Elaborado pelos autores a partir de Defra (2007).

A controvérsia acerca dos efeitos da regulação ambiental sobre os custos intrafirma - trade-off versus sinergia - e, por conseguinte, sobre sua competitividade, é ampliada quando se aborda a questão sob a perspectiva Norte-Sul. Nessa esfera, torna-se ainda mais claro que não se trata simplesmente de um debate acadêmico entre neoclássicos e tradições mais dinâmicas de pensamento econômico. Trata-se, outrossim, de preocupações políticas e de defesa de interesses nacionais estratégicos.

Nos PDs, é comum a argumentação de que a prática de dumping ambiental, protagonizada principalmente pelos PEDs, estaria incentivando o consumo de produtos importados calcados em processos produtivos excessivamente 
poluidores, em detrimento dos produtos nacionais, "ecologicamente sustentáveis". Assim, países com regulamentações, normas e práticas inferiores beneficiam-se ou geram vantagem comparativa no sistema mundial de comércio, que não existiria caso os custos de adoção das normas ou padrões internacionais fossem internalizados (GONÇALVES, 1998).

Conforme destaca Queiroz (2005), em 1972, a Organização para Cooperação e Desenvolvimento Econômico (OCDE) publicou um estudo intitulado "Princípios Orientadores Relacionados aos Aspectos Econômicos Internacionais das Políticas Ambientais". Esse trabalho orientou a formulação das políticas ambientais dos países-membros da OCDE no sentido de conscientizar agentes governamentais e a opinião pública da necessidade de se adotarem princípios para a compatibilização entre políticas ambientais e comerciais, destacadamente a harmonização de suas políticas ambientais.

Desde então, ainda que carecendo de evidências empíricas suficientes para justificar o argumento da competitividade, a resposta dada por significativa parcela dos países membros da OCDE vem se materializando sob a forma de concessão de subsídios compensatórios aos produtores locais e/ou a coerção sobre os países exportadores, mediante a pressão pela harmonização de seus padrões de produção com os padrões dos países importadores (STEVENS, 1993).

Tobey $(1990,1993)$ foi um dos primeiros autores a realizar uma análise reconhecidamente robusta sobre os reflexos dos diferentes níveis de rigidez de políticas ambientais nacionais sobre os padrões de comércio internacional. Empregou um modelo cross-section com base na teoria Heckscher-Ohlin-Vanek (HOV), para testar a hipótese de que o rigor das políticas ambientais está diretamente relacionado às exportações de bens poluição-intensivos. Os resultados estatísticos indicaram ausência de relação linear significativa entre as duas variáveis.

Na década de 1970, outros estudos teóricos examinaram o impacto de políticas ambientais sobre as vantagens comparativas. ${ }^{7}$ Utilizando uma análise de equilíbrio parcial, Baumol e Oates (1988) demonstraram que, se um país não impõe uma política ambiental quando outra nação o faz, então o primeiro aumentará sua vantagem comparativa ou reduzirá sua desvantagem comparativa na indústria intensiva em poluição. Essa mudança na vantagem comparativa conduzirá o primeiro país a especializar-se nessa indústria ao custo de degradação ambiental.

Porter e van der Linde (1995a) desafiaram esse tipo de resultado afirmando que as vantagens comparativas não dependem da eficiência estática ou da otimização dentro de restrições fixadas. Pelo contrário, é função da capacidade da firma (ou nação) em introduzir inovações e progressos a fim de deslocar essas restrições.

São exemplos desse tipo de abordagem os trabalhos de Siebert (1977), Pethig (1976), Baumol e Oates (1988) e Brander e Taylor (1997). 
Não só são contraditórias as opiniões nas construções teóricas, mas também nos estudos empíricos. O Quadro 2 ilustra uma espécie de linha do tempo, na qual estudos que avaliam os vínculos entre competitividade, padrões de comércio e políticas ambientais são classificados segundo seus resultados empíricos.

Nesses trabalhos, observa-se que as políticas ambientais impactam sobre a renda e o balanço de pagamentos dos países; de forma menos clara, sobre o nível de emprego; e, ainda em discussão, sobre os custos de produção e preços.

Quadro 2. Evolução do debate mundial acerca dos efeitos da regulação ambiental sobre a competitividade.
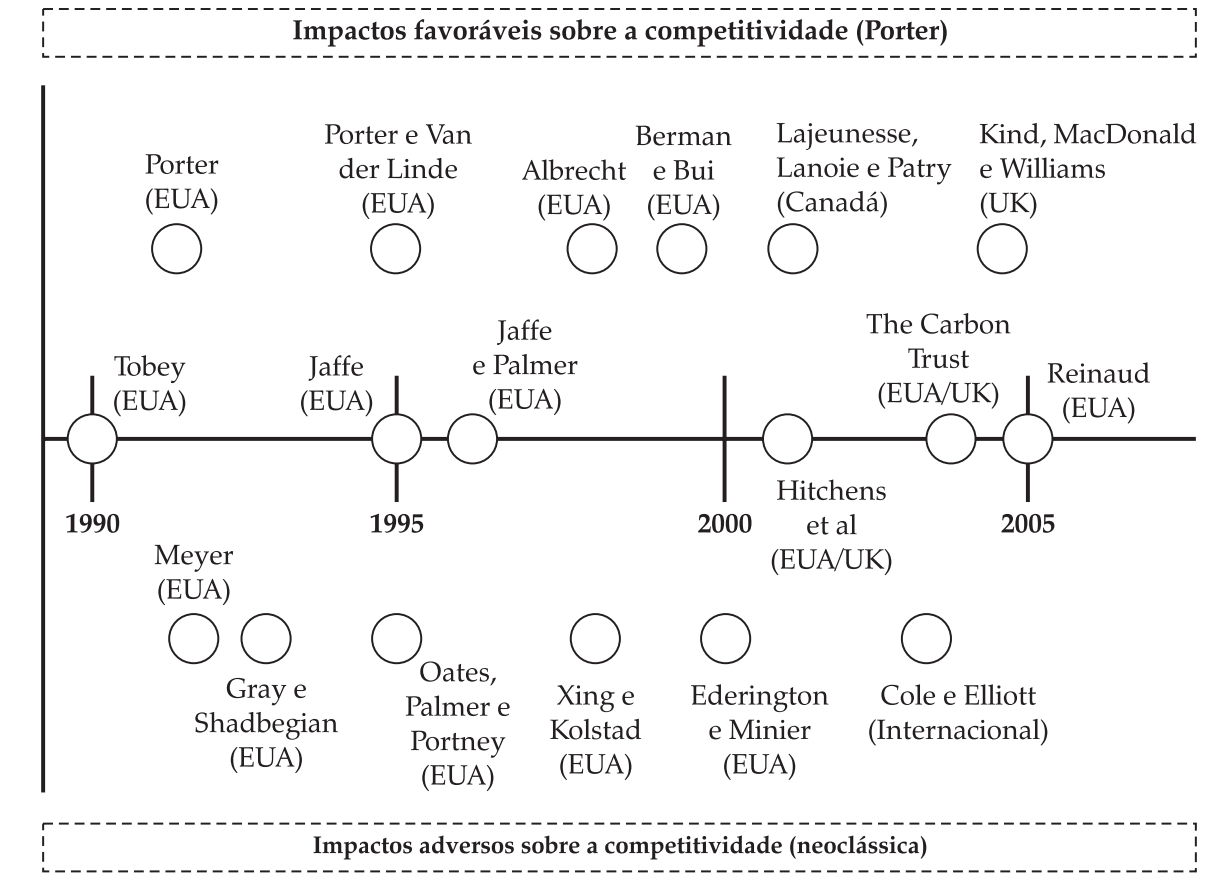

Fonte: Elaborado pelos autores a partir de Defra (2007).

Os estudos anteriormente citados mostram que os impactos das políticas comerciais sobre os padrões de comércio dependem do tipo de política e das condições econômicas sob as quais essas são aplicadas. Sua mensagem aos policy-makers não é exagerada: não há evidência suficiente nos estudos empíricos capaz de suportar as hipóteses sobre o impacto negativo das políticas ambientais sobre o comércio internacional. Por conseguinte, as políticas ambientais que são usualmente construídas para atender a objetivos sociais, ao menos, não deveriam causar efeitos adversos sobre o comércio. 
Comércio Internacional, Agricultura e Meio Ambiente: teorias, evidências e controvérsias empíricas

\section{Políticas ambientais, comércio e competitividade no setor agrícola ${ }^{8}$}

Os economistas utilizam o termo externalidade para designar efeitos paralelos, prejudiciais ou benéficos, decorrentes da produção, consumo ou distribuição de um bem em particular. Para produzir um bem, o agricultor, pecuarista ou silvicultor escolhe uma tecnologia e um conjunto de insumos visando maximizar lucro. No processo de produção, resíduos ou amenidades costumam surgir como um subproduto, sendo classificados como externalidades ambientais quando afetam o bem-estar dos indivíduos e seu gerador não paga ou recebe compensação pelos custos ou benefícios gerados.

As externalidades são frequentes quando os direitos de propriedade são mal definidos e/ou deficientemente fiscalizados. São comumente referidas como falhas de mercado, visto que não subestimam ou superestimam os preços de mercado.

As praticas agrícolas podem gerar externalidades positivas e negativas. Os agricultores não assumem todos os custos associados à produção, tais como erosão do solo, depleção da água, poluição da superfície e do lençol freático, desmatamento, perdas de biodiversidade e abuso de agroquímicos. Por outro lado, não colhem os benefícios de amenidades que podem ter produzido.

Os efeitos ambientais também surgem ou são exacerbados pela atuação governamental quando as políticas públicas deslocam os preços dos insumos e produtos agrícolas para longe do prevalecente na ausência de tais políticas. Alguns exemplos de programas de sustentação são a restituição pelas exportações e as cotas de importação. Falhas de mercado ocorrem em um ambiente competitivo quando os preços de mercado diferem dos custos sociais. Os produtores normalmente têm pouco incentivo para aderir a tecnologias mais limpas porque os custos "externos" ao processo não constituem parte dos seus custos privados. Visando contornar esse fato, cada vez mais são implementadas políticas sob a forma de regulações (padrões, proibições e restrições) ou mecanismos de incentivo (taxas, subsídios e licenças de comercialização).

Ainda que objetivem o alcance de metas ambientais, essas políticas acabam por afetar também a produção, o comércio, o investimento, as mudanças tecnológicas e os padrões de consumo.

\subsection{Seleção da política ambiental e seus instrumentos}

Para prover o setor privado de incentivos ao abatimento ambiental, os policymakers devem estar atentos a duas importantes questões: i) quanto da poluição deve ser reduzido? ii) que tipo de política é mais eficaz para atingir

8 Referência o estudo de Krissoff et al. (1996). 
a meta estipulada? Para responder à primeira questão, é necessário conhecer o valor atribuído pela sociedade aos danos gerados pela poluição e os benefícios líquidos da produção sob diferentes níveis de atividade econômica (Figura 1).

Figura 1. Nível ótimo de poluição e taxação.

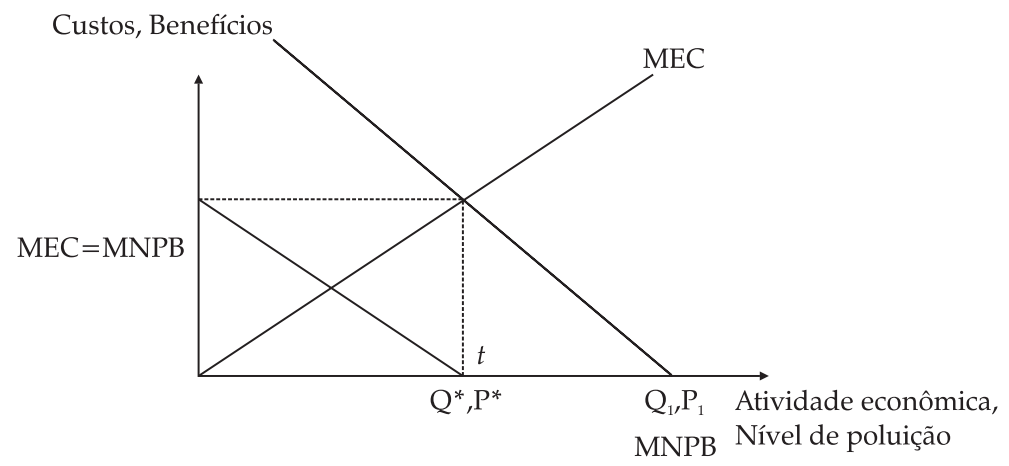

Fonte: Elaborado pelo USDA (1994), a partir de Pearce e Turner (1990).

De acordo com Pearce e Turner (1990), esses danos e benefícios podem ser representados por "custos marginais externos" (MEC) e "benefícios líquidos marginais privados" (MNPB). A curva MEC mede os custos adicionais da poluição para a sociedade, oriundos de mudanças nos níveis de produção. É positivamente inclinada para refletir o maior custo unitário dos danos ambientais sob elevados níveis de atividade econômica. A linha MNPB mostra os benefícios, menos os custos privados, variando ao produtor, segundo diferentes níveis de produção. Ignorando os custos sociais da produção, o produtor escolheria produzir ao nível $Q_{1}$, com um nível de poluição associado $P_{1}$, obviamente maior ao nível socialmente ótimo.

Quando os custos sociais são considerados, o nível social ótimo de atividade econômica e o associado nível de poluição se dão em patamar de produção no qual os benefícios marginais dos produtores se igualam aos custos marginais da poluição para a sociedade $\left(Q^{*}, P^{*}\right)$. Assim, a sociedade pode optar por eliminar a maioria senão toda a poluição, mas os custos dessa ação não devem exceder seus benefícios.

Por exemplo, embora todos os pesticidas possam ser banidos do uso agrícola, não se pode descartar a possibilidade de uma drástica redução da oferta de alimentos ou de seu encarecimento. Nesse caso, o produto e níveis de poluição devem ser menores que $Q^{*}$ e $P^{*}$. Uma abordagem economicamente mais racional é compelir o produtor a pagar uma quantia igual aos custos da poluição, por exemplo, uma taxa sobre a produção (igual a $t$ na Figura 1). A curva de benefício marginal líquido do produtor desloca-se para baixo com uma taxação de proporção t sobre cada unidade de produção, e a produção é 
$Q^{*}$, o ponto em que o benefício marginal líquido da produção é igual a zero. A taxação ótima é aquela que conduz a atividade econômica e poluição ao ponto ótimo social $\left(\mathrm{Q}^{*}\right.$ e $\left.\mathrm{P}^{*}\right)$, eliminando assim a diferença entre os custos sociais e privados.

Instrumentos de política ambiental incluem regulações, frequentemente chamadas de abordagem comando-controle, tais como incentivos com base em mecanismos do tipo taxas, subsídios e licenças de comercialização. As regulações podem assumir a forma de padrões ou cotas para níveis permitidos de eliminação; restrições sobre atividades econômicas em determinadas áreas de vulnerabilidade ambiental; proibições ao uso de produtos com efeitos ambientais potencialmente adversos; ou o conjunto de padrões para os produtos ou para os métodos de produção.

Os PDs empregam uma ampla variedade de regulações ambientais sobre os alimentos e a agricultura, como regulamentos sobre embalagens, rótulos e reciclagem dos resíduos; restrições sobre o uso da terra; restrições e proibições sobre o uso de determinados agroquímicos; cotas sobre produção e aplicação de fertilizante; restrições sobre o número de animais por hectare; e restrições ao transporte de poluentes.

\subsection{Política ambiental, comércio e bem-estar}

Como a política ambiental afeta a produção, o comércio e os preços? Para responder a pergunta, é necessário considerar uma série de fatores: i) a externalidade ocorre na produção ou no consumo? ii) a externalidade é local, transfronteiriça ou global? iii) a externalidade ocorre no país exportador, importador ou em ambos? iv) que tipo de política ambiental é adotada? v) a política ambiental é decretada no país exportador, importador ou em ambos? vi) o país exportador ou importador é grande o suficiente para afetar os preços mundiais do produto em questão?

Na Figura 2 foi considerado o caso de um país pequeno, onde o país poluidor não é capaz de influenciar os preços mundiais. A poluição ocorre na produção de um bem comercializado, mas os efeitos da poluição são estritamente locais. Assume-se que uma taxa ambiental é imposta sobre o produto do bem, tal como uma taxa cobrada sobre a produção animal para reduzir os efeitos do excesso da produção de resíduos sobre a água (Figura 2). A imposição de uma taxa ambiental reduzirá a produção doméstica, a poluição e as exportações. Mas, o nível de consumo doméstico permanecerá inalterado, visto que os consumidores se deparam com um preço internacional ainda constante. 
Figura 2. Impactos sobre o comércio e bem-estar de uma taxa ótima de controle ambiental em um país de pequenas dimensões.

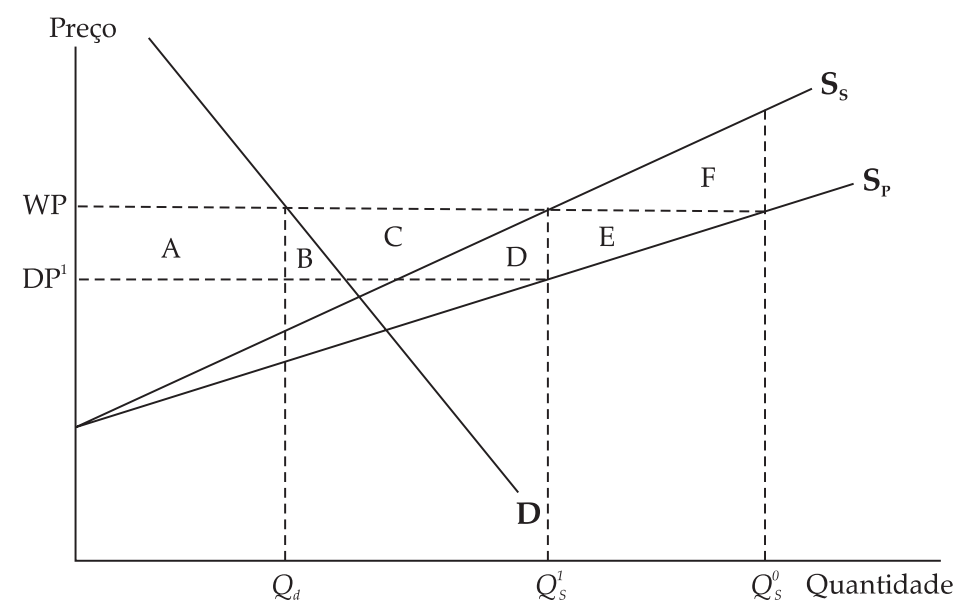

Fonte: USDA (1994).

A curva de oferta anterior à aplicação da taxa Sp reflete apenas os custos privados (ou internos) da produção. A curva de oferta posterior à aplicação da taxa Ss reflete os custos sociais totais de produção, formados pela soma dos custos privados e da sociedade impostos pela melhoria da água, por exemplo. Assim, a taxa internaliza os custos externos da operação da indústria, reduzindo a oferta da produção animal no mercado. A taxa é ótima porque elimina a diferença entre os custos privados e sociais para cada unidade potencial de produção. Antes da taxa, o país produz em $Q_{s}^{0}$, consome $Q_{d}$ e exporta $Q_{S}^{0}-Q_{d}$ em resposta ao nível de preço mundial WP. Após a taxa, os produtores, em resposta a um preço doméstico $D P^{1}$, reduzem a produção para $Q_{S}^{1}$. O consumo doméstico permanece inalterado e, dessa maneira, as exportações caem para $Q_{s}^{1}-Q_{d}$. A perda de bem-estar dos produtores é representada pela soma das áreas ABCDE, e o bem-estar dos consumidores não se altera. A receita governamental a partir da taxa cresce para ABCD, enquanto o dano ambiental diminui para EF. Em termos líquidos, o país exportador está em melhor situação pela área F. Assim, a taxa ambiental ótima constrói uma situação de melhora para o país. Enquanto os produtores domésticos são prejudicados, a sociedade encontra-se em melhor situação.

Na Figura 3, supõe-se a circunstância de uma externalidade similar, mas, agora, sendo o país grande o suficiente para influenciar o preço mundial do bem em questão. Assume-se a hipótese de que o país importador também produz o bem, mas não requer proteção ambiental, possivelmente devido à maior capacidade para absorver contaminantes ou por diferentes prioridades da sociedade com relação a esse tipo de poluição. A imposição de uma política 
ambiental mais rígida em um país exportador provavelmente resultará em redução comercial, pelo menos no curto prazo, e diminuirá a competitividade desse país. Isso ocorre porque a taxa ambiental aumenta o custo de produção para o exportador, reduzindo seu incentivo para produzir e exportar. Em função de ser um grande ofertador, uma parcela dos efeitos do aumento no custo de produção é deslocada para o exterior e aos consumidores domésticos, implicando que os produtores domésticos e consumidores locais e estrangeiros pagam o custo da redução da poluição doméstica.

Figura 3. Impactos sobre o comércio e bem-estar de uma taxa ótima de controle ambiental em um país de grandes dimensões.

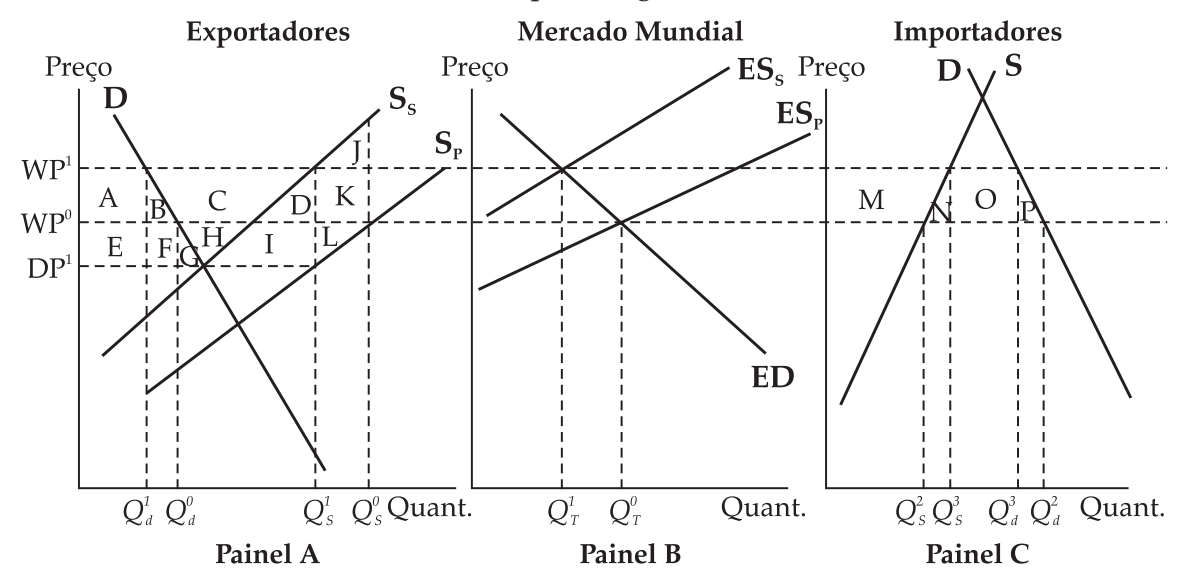

Fonte: USDA (1994).

O painel A, da esquerda, descreve as condições de mercado em um país exportador antes e depois da implementação da taxa ambiental. Como na Figura 2, a curva de oferta antes da aplicação da taxa $S_{p}$ reflete os custos privados da produção, enquanto a curva de oferta $S_{p}$ reflete os custos sociais totais da produção. $\mathrm{O}$ painel $\mathrm{B}$ mostra que o efeito dos incentivos ao amortecimento da produção no país exportador é para reduzir a oferta ao mercado mundial, representado pelo deslocamento na posição do excedente da oferta de $\mathrm{ES}_{\mathrm{p}}$ para $\mathrm{ES}_{\mathrm{s}}$. Esse deslocamento reduz o comércio do montante inicial $Q_{T}^{0}$ para o nível final após taxa $Q_{T}^{1}$ e direciona a produção global aos importadores.

Parte doônus da taxa sobre os produtores também recai sobre os consumidores domésticos e estrangeiros. Isso ocorre em função de a participação do país taxado no mercado mundial do bem agrícola em questão ser suficientemente grande para elevar os preços quando sua oferta diminui em resposta a política ambiental aplicada. Um país pequeno, em contraste (Figura 2), não é capaz de alterar os termos de troca em seu favor quando aplica uma política ambiental cujo resultado é a redução da produção. 
Uma política ambiental implementada em um grande país exportador, como definido anteriormente, afeta o bem-estar de todos os participantes do mercado. No país exportador, produtores e consumidores sofrem perdas de bem-estar iguais ao conjunto das áreas EFGHIL e AB, respectivamente. A receita do governo a partir da taxa, não obstante, aumenta como representado pela área ABCDEFGHI, e o custo do dano social gerado a partir da produção do bem diminui no montante da área JKL. Por conseguinte, quando avaliados de forma líquida, os países exportadores se encontram em melhor posição pelas áreas CD (efeito termos de troca) e JK (efeito externalidade). No que diz respeito aos países importadores (painel $\mathrm{C}$ ), os produtores beneficiam-se do aumento no preço mundial do produto agrícola (área M), mas os consumidores sofrem perdas de bem-estar (área MNOP).

O tamanho da taxa em relação aos outros custos de produção é um elemento fundamental na determinação de quão significativo serão os efeitos da mesma sobre a produção e o comércio. $\mathrm{O}$ país exportador avaliado como um todo - tendo em conta a percepção da sociedade no que tange aos benefícios ambientais - permanecerá em melhor situação. A imposição de uma taxa ótima assegura que os benefícios gerados a partir da redução da poluição compensam os custos aos produtores e consumidores, induzidos pela taxa.

As políticas ambientais também podem influenciar a composição da produção agrícola e o comércio. Como a estrutura de custo da atividade regulada aumenta relativamente à das demais atividades, recursos produtivos se deslocarão em direção aos setores de menor rigor ambiental. Parte dos recursos pode ser atraída, inclusive, por segmentos de fora da agricultura, na medida em que esse setor se torna mais restritivo que outras indústrias. Esses efeitos na composição do produto também influenciam a combinação relativa de produto agrícola e comércio. Por exemplo, a produção e a exportação de produtos que fazem uso menos intensivo de fertilizantes, tal como a soja, podem ser encorajadas quando uma taxa sobre o uso de fertilizantes for implementada.

O efeito composição pode também influenciar a relação entre a produção primária e a de produtos agrícolas processados. Restrições ao uso de defensivos ou limitações à densidade animal podem reduzir a produção in natura de açúcar, frutas, vegetais e produtos animais. Um país pode, então, importar mais produtos primários para processar ou importar os produtos processados e deslocar recursos para fora do agronegócio.

Conforme ficou evidenciado, segundo a teoria neoclássica, as políticas ambientais influenciam o nível e composição do comércio devido aos seus efeitos sobre os custos de produção. Como visto nas seções anteriores, a direção e magnitude dos efeitos da regulação ambiental variam devido a uma série de fatores, dentre os quais a rigidez e tipo de medida ambiental adotada. Tudo o mais permanecendo constante, espera-se que o rigor ambiental seja proporcional ao nível de degradação, uma vez que as sociedades tendem a 
proteger seus recursos de acordo com os problemas ambientais mais urgentes, $\mathrm{e}$ não preventivamente. A maior densidade animal observada na União Européia e os problemas relacionados ao tratamento dado ao esterco, por exemplo, conduziram à ratificação da Diretiva dos Nitratos, uma das mais restritivas medidas de controle de poluição de nitratos do mundo.

Outro fator a considerar é a amplitude de aplicação das medidas ambientais. Uma regulação ambiental destinada a atingir uma determinada meta em uma particular localização geográfica ou problema específico pode resultar em custos geograficamente diversos.

\subsection{Políticas ambientais e seus efeitos à competitividade: a controvérsia Norte-Sul}

A atividade agrícola, ao mesmo tempo em que cumpre um papel fundamental para a erradicação da fome no mundo, está diretamente associada à demanda insustentável pelos recursos naturais. Segundo a Organização das Nações Unidas para a Agricultura e Alimentação (FAO, 2003), a produção agropecuária é a principal fonte antropogênica de gases responsáveis pelo efeito estufa e contribui de forma significativa para outros tipos de contaminação do ar e da água. Além disso, os métodos agrícolas, florestais e pesqueiros são as principais causas da perda de biodiversidade no mundo.

A degradação ambiental no setor agrícola está associada, principalmente, à expansão da fronteira produtiva, à utilização de defensivos químicos e ao arranjo ineficiente destes e dos demais insumos. Da mesma forma, particularmente no caso das commodities agrícolas, a necessidade de contínuos ganhos de produtividade visando à transposição das barreiras protecionistas no mercado internacional é tida como incompatível com padrões ecologicamente sustentáveis de produção.

De acordo com Procópio Filho, Vaz e Tachinardi (1994), existe um amplo consenso de que barreiras comerciais e subsídios na área agrícola provocam significativas distorções de mercado em prejuízo aos PEDs e induzem modos ineficientes de produção. Há evidências de que o protecionismo agrícola não somente pode falhar na ajuda ao ambiente como pode ser fonte importante de sua degradação.

Entretanto, os mesmos autores alertam que os efeitos da liberalização não podem ser tidos como responsáveis imediatos dos problemas ambientais originados a partir da produção agrícola. No longo prazo, os efeitos estruturais da liberalização do comércio agrícola dependerão do seu impacto direto sobre o uso de insumos e sobre o aporte de tecnologias maximizadoras do uso do solo, da água e dos insumos produtivos, sem causar ou ampliar os danos ambientais (efeito tecnológico positivo). 
De qualquer forma, a política de subsídios adotada pelos principais países da OCDE, ao reduzir os preços internacionais das commodities agrícolas no intuito de garantir a competitividade de seus produtos, contribui para a estagnação econômica dos PEDs. Em contrapartida, cada vez mais, os PEDs se veem obrigados a intensificar o uso de defensivos agrícolas e outras práticas degradantes ao meio ambiente, a fim de não verem abalada a competitividade dos seus principais produtos destinados à exportação.

Os dados estimados para o consumo mundial de agroquímicos na década de 1990 evidenciam o efeito ambíguo dessa conjuntura e revelam outra dicotomia entre as duas regiões (Figura 4). Enquanto as legislações ambientais nacionais dos PDs eram orientadas no sentido de criar incentivos ao abandono a práticas potencialmente agressivas à paisagem rural e mantinham a política de subsídios ao setor, nos PEDs a utilização em larga escala dos insumos modernos era proclamada como medida fundamental para resguardar a competitividade de seus produtos agrícolas no exterior.

Dada a atual tendência de esses países procurarem intensificar a aplicação extraterritorial de normas e padrões ambientais, fitossanitários e zoosanitários dentro de um contexto de harmonização dos mesmos, intensifica-se o risco de os PEDs virem a confrontar-se com medidas restritivas no comércio agrícola principalmente se as legislações ambientais destes últimos não forem interpretadas como congruentes com os padrões produtivos e ambientais daqueles países (PROCÓPIO FILHO, VAZ e TACHINARDI, 1994).

Figura 4. Consumo mundial e regional de fertilizantes (em milhares de toneladas).

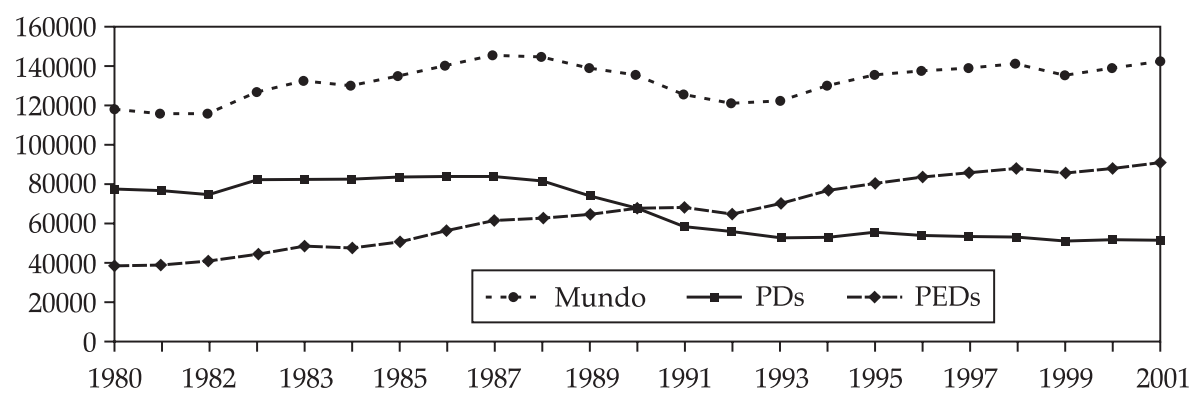

Fonte: Faostat (www.fao.org).

\section{O setor agroexportador brasileiro e suas interfaces com o meio ambiente}

As características que atualmente marcam a agricultura brasileira são completamente distintas das verificadas até o início da década de 1950. A partir do final da Segunda Guerra Mundial, os antigos modelos de plantations 
e de subsistência foram gradualmente cedendo espaço à chamada "agricultura moderna", caracterizada pela crescente especialização, elevada produtividade e direta integração aos demais sistemas produtivos.

Paralelamente à maturação desse processo, ao longo da década de 1980, ocorre a reversão da postura intervencionista do Estado na agricultura, manifestada até então, sobretudo, por meio da política de garantia de preços mínimos e crédito rural subsidiado (Dias e Amaral, 2001). A partir daí, e intensamente após a abertura comercial nos anos 1990, a agricultura brasileira é definitivamente orientada a uma economia de mercado.

No campo externo, houve uma "reprimarização" das trocas internacionais brasileiras em decorrência do fato de somente os produtos agrícolas terem obtido crescimento de competitividade na última década (SILVA, 2004). Na ótica de Lustosa e Young (2002), esse fenômeno está diretamente associado à volta das vantagens comparativas estáticas como elemento dominante na determinação das metas de produção e exportação dos PEDs.

Lustosa e Young (2002) assinalam, ainda, que o fato de as exportações dos demais setores produtivos não terem reagido de acordo com as expectativas para o período sucessório à abertura comercial do início da década de 1990 também cooperou para o crescimento da participação do setor agropecuário na pauta total. Os dados disponibilizados pela Funcex (2008) mostram que, enquanto as exportações brasileiras totais cresceram em média 4,28\% a.a. entre 1994 e 2003, as vendas externas agropecuárias expandiram-se em 10,9\% a. a.

Não obstante o comportamento favorável da demanda externa tenha sido fundamental para a expansão das exportações agropecuárias, são muitos os condicionantes internos que também contribuíram decisivamente para esse sucesso. Entre eles, destaca-se a consolidação de um ambiente institucional favorável à produção de grãos. Segundo dados da Companhia Nacional do Abastecimento (CONAB, 2008), entre as safras 1993/1994 e 2002/2003, a produção brasileira de grãos saltou de 76,04 para 123,17 milhões de toneladas (62\%), explicada pelos ganhos de produtividade; a variação da fronteira agrícola foi de apenas $12,4 \%$.

A mensuração dos impactos dessa expansão da safra agrícola em termos de sustentabilidade ambiental é complexa e envolve a avaliação de diversos fatores. Se, por um lado, o melhor aproveitamento da terra permitiu a conservação de áreas ainda inexploradas, passíveis de aproveitamento pela agricultura, por outro, a expansão das monoculturas de exportação transformou a paisagem natural e intensificou o uso de insumos considerados degradantes ao meio ambiente. Além disso, o caráter difuso da contaminação faz com que seja difícil determinar a contribuição das distintas atividades no impacto ambiental global.

De acordo com a FAO (1997), as principais categorias de impactos ambientais relacionados ao cultivo agrícola são:

- Os efeitos para a saúde humana, causados por fertilizantes, defensivos agrícolas e metais pesados, por meio da contaminação da água e de 
produtos alimentícios, além dos depósitos ácidos causados por emissões de amoníaco dos fertilizantes;

- A erosão do solo e a conseguinte sedimentação das águas costeiras e superficiais que causam danos à infraestrutura e à propriedade;

- Perdas na fauna e flora silvestres e de diversidade biológica, bem como danos ao equilíbrio e resistência dos ecossistemas como resultado da degradação do solo; contaminação de águas costeiras, superficiais e freáticas, causada por fertilizantes e agrotóxicos.

Quando se pretende elucidar as interfaces entre agricultura e meio ambiente e analisar o comportamento das principais variáveis anteriormente citadas, percebese que a condição brasileira é preocupante. Segundo o IBGE (2002), embora a agricultura moderna esteja atingindo níveis de produção e de produtividade que atendam às exigências do mercado, sua expansão tem gerado impactos ambientais que comprometem a sustentabilidade dos ecossistemas agrícolas.

Com o auxílio dos dados referentes à venda de fertilizantes, pode-se concluir que há uma forte tendência à intensificação do uso desse insumo na produção agrícola brasileira (Figura 5). Entre os anos de 1990 e 2003, a comercialização média de fertilizantes por hectare (ha) cultivado cresceu aproximadamente $180 \%$.

Quando se analisa a evolução do consumo de defensivos agrícolas, o mesmo fenômeno volta a ocorrer. Para o IBGE (2002, p. 76), “os agrotóxicos... estão entre os principais instrumentos do atual modelo de desenvolvimento da agricultura brasileira, e seu uso intensivo está associado a agravos à saúde da população, tanto dos consumidores quanto dos trabalhadores que lidam diretamente com os produtos, à contaminação de alimentos e à degradação do meio ambiente".

Figura 5. Quantidade média de fertilizantes comercializada, por área plantada, no período 1990 - 2003 (kg/ha).

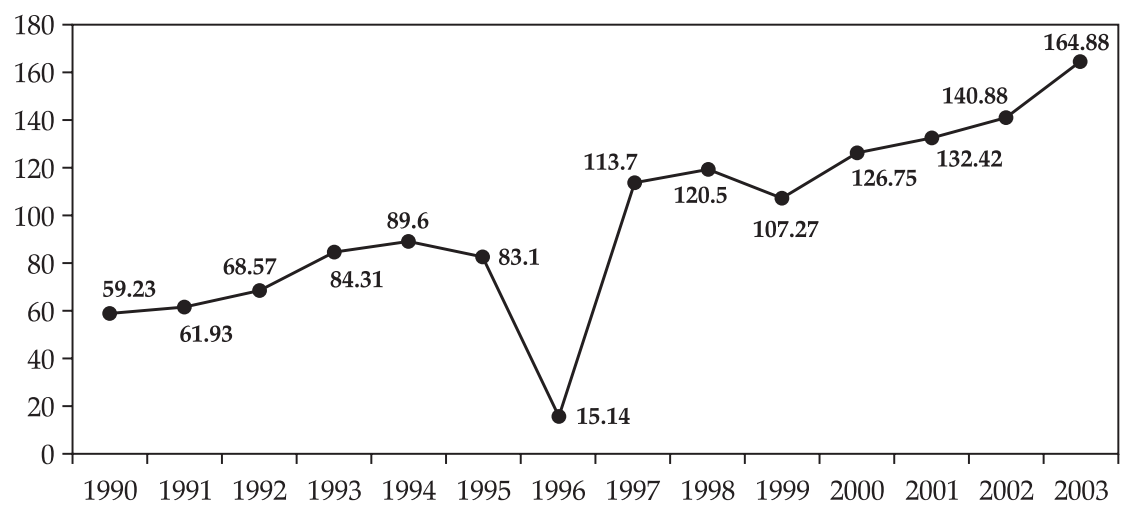

Fonte: Ministério da Agricultura (2006) e IBGE (2008). 
Impulsionado pelo excelente desempenho da agricultura, o setor de defensivos triplicou seu faturamento na última década. O mercado brasileiro, que era de US\$ 942 milhões em 1992, chegou a US\$ 3,1 bilhões em 2003 e, segundo o presidente da Associação Nacional de Defesa Vegetal (Andef), continua promissor, colocando-se em terceiro lugar no ranking mundial (GAZETA MERCANTIL, 2004).

Esse significativo ganho de faturamento reflete, entre outros fatores, o intenso crescimento do consumo de defensivos no Brasil. Enquanto em 1990 a quantidade média comercializada era de apenas $1,13 \mathrm{~kg}$ de princípio ativo por hectare cultivado, as estimativas para o ano de 2003 apontavam para $3 \mathrm{~kg} / \mathrm{ha}$.

A intensificação do consumo de agrotóxicos e fertilizantes na agricultura brasileira foi favorecida pela abertura comercial a partir de 1989. Para Homem de Melo (2002, p.6), "entre o conjunto de variáveis que tiveram comportamento (economicamente) favorável a partir da liberalização comercial estão a melhoria (até 1997) das cotações internacionais de produtos agropecuários e a redução dos preços reais de fertilizantes e defensivos agrícolas".

Com base nesses indicadores, a expansão da agricultura moderna no Brasil vem consolidando a tendência de processos produtivos que contribuem para a degradação ambiental, sendo natural que nos próximos anos se intensifique o conflito de interesses entre os produtores rurais e a sociedade civil, cujas demandas ambientais crescem. Sob o ponto de vista econômico, um alerta é que o uso mais intensivo de fertilizantes e defensivos agrícolas ocorre justamente nas principais regiões exportadoras de produtos agrícolas (Centro-Oeste, Sudeste e Sul).

Figura 6. Utilização de fertilizantes e defensivos agrícolas por unidade de área cultivada ( $\mathrm{kg} / \mathrm{ha})$ nas grandes regiões brasileiras, em 2000.

\section{Fertilizantes}

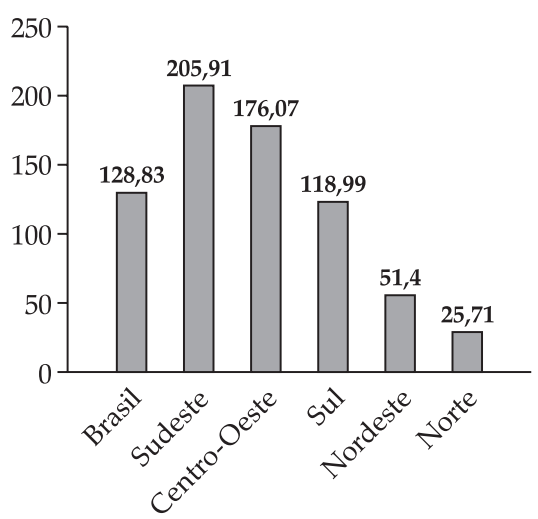

Defensivos agrícolas

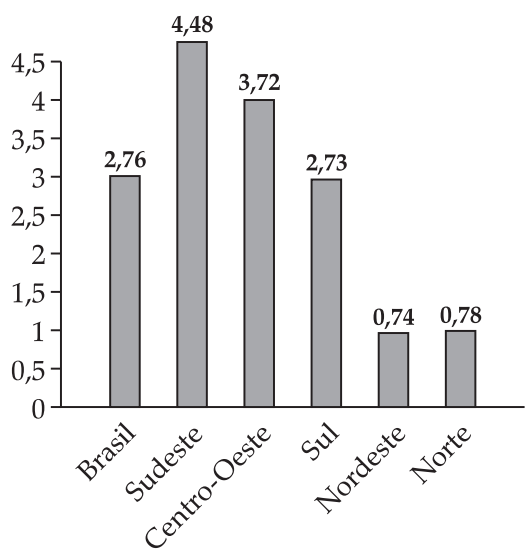

Nota: Todos os dados referentes ao consumo de fertilizantes e defensivos agrícolas estão expressos, respectivamente, segundo a quantidade de nutrientes da composição (N, P2O5 e K2O) e quantidade de ingrediente ativo. Fonte: Sindag (2006) e IBGE (2002). 
As variáveis descritas na Figura 6 permitem concluir que há evidências de um padrão de especialização diferenciado, que seria mais intensivo na utilização de agrotóxicos e fertilizantes, nas principais regiões produtoras de commodities agrícolas destinadas ao mercado internacional. Conforme discutido, isso é característico de regiões onde o efeito composição agrava a degradação dos recursos naturais, tornando-as vulneráveis às normas e regulamentações ambientais acordadas no âmbito do comércio de bens.

Dessa forma, diante da atual tendência brasileira de intensificação do uso de insumos agrícolas degradantes ao meio ambiente e de um cenário externo que caminha em direção à imposição de rigorosos padrões ambientais na produção agrícola, é inevitável que os produtos brasileiros passem a encontrar barreiras não tarifárias cada vez maiores.

\section{Conclusões}

Este estudo apresentou uma visão geral e ampla do debate teórico e empírico pela identificação dos vínculos econômicos entre comércio e meio ambiente. Percebe-se que, tanto o estudo dos impactos gerados a partir da aplicação das políticas ambientais sobre a competitividade, os termos de troca ou bem-estar, quanto à análise das relações entre liberalização comercial e sustentabilidade, podem chegar a conclusões radicalmente opostas segundo o método empregado, o horizonte de tempo, a região e os segmentos econômicos abordados.

Diante da impossibilidade de generalizar conclusões acerca do tema, parece mais apropriado avaliar os resultados de todos os estudos consistentes, pois cada um projeta uma luz sobre uma questão ambiental-econômica específica de interesse, contribuindo para identificar alternativas políticas adequadas. Contudo, a despeito de os vínculos entre desempenho comercial e ambiental não serem suficientemente nítidos, as políticas dos PDs, atendendo à demanda de seus produtores e consumidores, de forma geral são desenhadas para incentivar o crescimento das exportações e limitar a entrada de produtos cuja procedência seja ambientalmente duvidosa. Paralelamente a esse processo, é crescente a concessão de incentivos econômicos para o desenvolvimento de indústrias limpas e a internalização dos custos ambientais no setor rural.

$\mathrm{O}$ fato de a produção agrícola ser relativamente mais subsidiada que a industrial, por exemplo, pode tanto incitar a adoção de insumos sensíveis do ponto de vista ambiental, quanto estimular a produção a um nível insustentável do ponto de vista ambiental mediante seu efeito redutor de custos. De forma geral, o impacto das políticas ambientais direcionadas ao setor agrícola sobre a produção, o comércio e os preços do setor dependerá do tipo de externalidade combatida ou estimulada, do tipo de política ambiental adotada e da posição e dimensão do país que impõe a política. 
Historicamente os PEDs condenam o arranjo de medidas protecionistas sustentadas no setor agrícola pelos PDs e identificam nestas uma razão para um ajuste apenas moderado de sua produção a exigências mais rigorosas. A expansão da agricultura moderna no Brasil vem consolidando a tendência de emprego de processos produtivos com elevado potencial degradante ao meio ambiente. Tal fenômeno, além de gerar desdobramentos internos pouco desprezíveis, contribui para situar o país na alça de mira dos movimentos ambientalistas internacionais e dificultar a inserção de seus produtos no mercado internacional, cada vez mais reflexo das questões ambientais globais.

Assim, faz-se necessária a definição de políticas ambientais sinérgicas, capazes de dotar a agricultura brasileira de padrões mais sustentáveis de produção, sem comprometer sua competitividade. Contudo, tal ação somente poderá revelar-se efetiva se integrada em um escopo maior, que envolva a construção de uma agenda local de pesquisas para o tema comércio-meio ambiente, especificamente para o setor agrícola.

\section{Referências Bibliográficas}

ALMEIDA, L. T. Harmonização Internacional de Políticas Ambientais. In: XX Congresso da Latin American Studies Association (LASA), 1997, Guadalajara. XX Congress of Latin American Studies Association: Proceedings, 1997.

ALMEIDA, L. T. As interações entre comércio e meio ambiente. In: Braga, S. B.; Miranda, L. C. (Org.) Comércio e meio ambiente: uma agenda para a América Latina e Caribe. Brasília: MMA/SDS, 2002, p. 27 -40.

ANDERSON, K. (1992). Effects on the environmental and welfare of liberalizing world trade: the cases of coal and food. In: Anderson, K. e Blackhurst, R (eds.). The Greening of World Trade Issues, Ann Arbor: University of Michigan Press and London: Harvester Wheatsheaf, chapter 8.

BARRETT, S. (1994). Strategic Environmental Policy and International Trade, Journal of Public Economics, Amsterdam, v. 54, n. 3, p. 325-38, Jul. 1994.

BAUMOL, W. J. Environmental Protection, International Spillovers and Trade, Wicksell Lecture, Stockholm: Almquist e Wicksell, 1971.

BAUMOL, W.; OATES, W. E. The Theory of Environmental Policy. New Jersey: Prentice-Hall, 1975.

BAUMOL, W.; OATES, W. E. The Theory of Environmental Policy. 2. ed. New York: Cambridge University Press, 1988. 
BHAGWATI, J. Trade and the environment: the false conflict? In: ZAELKE, D.; ORBUCH, P.; HOUSMAN, R. F. (eds.), Trade and the Environment: Law, Economics, and Policy, Washington, DC: Island Press, 1993, p. 159-190.

BIRDSALL, N.; WHEELER, D. Trade policy and industrial pollution in Latin America: where are the pollution havens? The Journal of Environment $\mathcal{E}$ Development, San Diego, v. 2, n.1, p. 137-149, Jan. 1993.

BRANDER, J. A.; TAYLOR, M. S. International trade between consumer and conservationist countries. Resource and Energy Economics, Amsterdam, v. 19, n. 4, p. 267-297, Nov. 1997.

BRASIL. MINISTÉRIO DA AGRICULTURA, PECUARIA E ABASTECIMENTO. Dados estatísticos. Disponível em: < http://www.agricultura.gov.br>. Acesso em: 12 out. 2006.

CHICHILNISKY, G. North-South trade and the globe environment. American Economic Review, Nashville, v. 84, n. 4, p. 851-874, Sep. 1994.

CONFEDERAÇÃO NACIONAL DA AGRICULTURA; CENTRO DE ESTUDOS AVANÇADOS EM ECONOMIA APLICADA. CNA/CEPEA. PIB do Agronegócio. Disponível em: <http://www.cepea.esalq.usp.br/pib>. Acesso em: 23 jan. 2007.

COMPANHIA NACIONAL DE ABASTECIMENTO. Central de informações agropecuárias. Disponível em: < http://www.conab.gov.br/conabweb/index. php?PAG=101>. Acesso em: 12 jan. 2006.

COPELAND, B. R.; TAYLOR, M. S. North-South trade and the environment, Quarterly Journal of Economics, Cambridge, v.109, n. 3, p. 755-787, Aug. 1994.

DALY, H. E. The Perils of Free Trade, Scientific American, New York, v. 269, p. 5057, Nov. 1993.

DEAN, J. M. Testing the impact of trade liberalization on the environment: theory and evidence. In: FREDRIKSSON, P.G. (ed.). Trade, Globe Policy, and the Environment, World Bank, Washington, DC: World Bank, 1999, p. 55-61.

DEPARTMENT FOR ENVIRONMENT, FOOD AND RURAL AFFAIRS. DEFRA. Exploring the relationship between environmental regulation and competitiveness - a literature review. 2007. Disponível em: <http://randd.defra. gov.uk/Document.aspx?Document=SD14012_3476_FRP.pdf $>$ Acesso em: 12 set. 2007.

DIAS, G. L. S.; AMARAL, C. M. Mudanças estruturais na agricultura brasileira. Santiago do Chile: CEPAL, 2001. Disponível em: <www.nuca.ie.ufrj.br/infosucro/ biblioteca/agricultura/ias_mudancas.pdf>. Acesso em: 17 jun. 2006. 
DUA, A.; ESTY, D. C. Sustaining the Asia Pacific Miracle: environmental protection and economic integration. Washington, DC: Pearson Institute,1997, 208 p.

EKINS, P.; FOLKE, C.; COSTANZA, R. Trade, environment and development: the issues in perspective. Ecological Economics, Amsterdam, v. 9, n. 1, p. 1-12, Jan. 1994.

ELISTE, P.; FREDRIKSSON, P. G. Does Open Trade Result in a Race to the Bottom? Cross-Country Evidence, mimeo, 1998, World Bank.

ESTY, D. C. Greening the GATT: Trade, Environment, and the Future, Washington, DC: Peterson Institute, 1994, p. 319.

ESTY, D.C.; GERADIN, D. Market Access, Competitiveness, and Harmonization: Environmental Protection in Regional Trade Agreements, The Harvard Environmental Law Review, v. 21, n. 2, p. 265-336, Jan. 1997.

FOOD AND AGRICULTURE ORGANIZATION OF UNITED NATIONS. FAO. Perspectivas para la agricultura e el medio ambiente en los próximos treinta años. Roma: $\mathrm{FAO}, 2003$.

FOOD AND AGRICULTURE ORGANIZATION OF UNITED NATIONS. FAO. Posibles efectos de los reglamentos medioambientales em el cultivo, elaboracion y comercio de los dos principales cultivos oleaginosos anuales y perennes. Roma: 1997. Disponível em: <http://www.fao.org >. Acesso em: 5 jul. 2005.

FUNDAÇÃO CENTRO DE ESTUDOS DO COMÉRCIO EXTERIOR. FUNCEX. Base de dados estatísticos. Disponível em: < http://www.funcex.com.br/basesbd/ cad_base.asp?tp=1>. Acesso em: 12 jan. 2007.

GAZETA MERCANTIL. Defensivos. (Suplemento Projetos de Mercado: Agronegócios, pág. 7 de 05/08/2004). In: Sindicato Nacional da Indústria para Defesa Agrícola (SINDAG). Acesso em 22 nov. 2004 < http://www.sindag.com.br/ new/noticias/interna.php?cod $=585>$.

GONÇALVES, R. Meio ambiente e a economia política do comércio internacional. Revista brasileira de economia política, Rio de Janeiro, n. 3, p. 101-113, dez. 1998.

GROSSMAN, G. M.; KRUEGER, A. B. Environmental Impacts of a North American Free Trade Agreement. In: GARBER, P. (Ed.). The Mexico-US Free Trade Agreement. Cambridge, Ma: MIT Press, 1993, 317p.

GUTIERREZ, M. B. S. Comércio e meio ambiente no Mercosul: algumas considerações preliminares. Texto para Discussão, n. 470, 1997. Acesso em: 13/01/2006. Disponível em: <www.ipea.gov.br/pub/td/1997/td_0470.pdf>.

HAWKEN, P.; LOVINS, A. B.; LOVINS, L. H. (1999), Natural Capitalism: Creating the Next Industrial Revolution. Boston: Little, Brown. 396 p. 
HETTIGE, H.; R. LUCAS, R. A.; WHEELER, D. The Toxic Intensity of Industrial Production: Global Patterm. The American Economic Review, v. 82, n. 2, Trends and Trade Policy, Papers and Proceedings of the Hundred and Fourth Annual Meeting of the American Economic Association, p. 478-481, May 1992.

HOMEM DE MELO, F. Abertura comercial e o papel dos aumentos de produtividade na agricultura brasileira. São Paulo, 2002. Disponível em: <www.ifb.com.br/ documentos/hdemelo.pdf>. Acesso em: 24 jul. 2006.

INSTITUTO BRASILEIRO DE GEOGRAFIA E ESTATÍSTICA. IBGE. Indicadores de desenvolvimento sustentável. Rio de Janeiro: IBGE, 2002. Disponível em: <http://www2.ibge.gov.br/pub/indicadores_desenvolvimento_sustentável >. Acesso em: 13 jan. 2006.

INSTITUTO BRASILEIRO DE GEOGRAFIA E ESTATÍSTICA. IBGE. Produção Agrícola Municipal. Disponível em: < http://www.ibge.gov.br/home/estatistica/ economia/pamclo/2002_2006/default.shtm>. Acesso em: 14 jan. 2008.

INTERNATIONAL INSTITUTE OF SUSTAINABLE DEVELOPMENT. IISD. Manual de Medio Ambiente y Comercio. Winipeg: 2001. Disponível em: <www.iids.org/trade/ handbook>. Acesso em: 13 jan. 2003.

INTERNATIONAL INSTITUTE OF SUSTAINABLE DEVELOPMENT. IISD. State of trade and environment research: building a new research agenda. Winipeg, 2004 Disponível em: < http://www.iisd.org/pdf/2004/trade_state_of_trade_env_ research.pdf>. Acesso em: 12/04/2007.

JAFFE, A.B.; PETERSON, S. R.; PORTNEY, P. R.; STAVINS, R. N. Environmental Regulation and the Competitiveness of US Manufacturing: What Does Evidence Tell US. Journal of Economic Literature, Nashville, v. 33, n. 1, p. 132-163, Mar. 1995.

KENNEDY, P.W. Equilibrium Pollution Taxes in Open Economics with Imperfect Competition. Journal of Environmental Economics and Management, Beltsville v. 27, p.49-63, Jul. 1994.

KRISSOFF, B.; BALLENGER, N.; DUNMORE, J.; GRAY, D. Exploring Linkages Among Agriculture, Trade, and the Environment: Issues for the Next Century. Natural Resources and Environment Division, Economic Research Service, U.S. Department of Agriculture. Agricultural Economic Report No. 738, 1996. Disponível em: <http://www.ers.usda.gov/publications/aer738/Aer738.pdf>. Acesso em: 8 jul. 2008.

LEE,H.; ROLAND-HOLST, D. International Trade and Transfer of Environmental Costs and Benefits. OECD Development Centre Working Papers 91, OECD Development Centre. 1993. Disponível em: < http://ideas.repec.org/p/oec/ devaaa/91-en.html>. Acesso em: 23 jul. 2007. 
LOW, P; YEATS, A. Do “Dirty" Industries Migrate? In: LOW, P. (Ed.). International Trade and the Environment. Washington, DC: World Bank, 1992.

LUSTOSA, M. C. J.; YOUNG, C. E. F. Competitividade e meio ambiente. In: Sérgio Braga; Luiz Camargo de Miranda. (Org.). Comércio e meio ambiente: uma agenda para a América Latina e Caribe. Brasília: Ministério do Meio Ambiente, 2002, p. 41-60.

MAGEE, S.; FORD, W. F. Environmental Pollution, the Terms of Trade, and the Balance of Payments of the United States. Kyklos, Zurich, v. 25, n. 1, p.101-18, Feb. 1972.

PEARCE, D.; TURNER, R. Economics of Natural Resources and the Environment. Baltimore: The Johns Hopkins University Press, 1990.

PETHIG, R. Pollution, Welfare and Environmental Policy in the Theory of Comparative Advantage. Journal of Environmental Economics and Management, Orlando, v.2, n. 3, p.160-169, Feb. 1976.

PORTER, M. E. America's Green Strategy. Scientific American, v. 264, p. 264-168, Apr. 1991.

PORTER, M. E.; LINDE, C. van. der. Toward a New Conception of the Environment-Competitiveness Relationship. Journal of Economic Perspectives, Nashville, v. 9, n. 4, p. 97-118, Aut. 1995a.

PORTER, M. E.; LINDE, C. van der. Green and Competitive: Ending the stalement. Harvard Business Review, New York, v.73, n. 5, 120-134, Sep.1995b.

PROCÓPIO FILHO, A. (Coord.); VAZ, A. C.; TACHINARDI, M. H. Ecoprotecionismo: comércio internacional, agricultura e meio ambiente. Estudos de Política Agrícola. IPEA, n.17, 1994.

QUEIROZ, F. A. Meio ambiente e comércio na agenda internacional: a questão ambiental nas negociações da OMC e dos blocos econômicos regionais. Ambiente e Sociedade, Campinas, vol. 8, n. 2, p. 125-146, Jul./Dez. 2005.

RAUSCHER, M. On Ecological Dumping. Oxford Economic Papers, Oxford, v.46, n.5, p.822-840, Oct.1994.

SIEBERT, H. Environmental Quality and the Gains from Trade. Kyklos, Zurich, v.30, n.4, p.657-673, Oct. 1977.

SILVA, C. R. L. Evolução do comércio agrícola brasileiro segundo o valor adicionado. In: XLII CONGRESSO DA SOCIEDADE BRASILEIRA DE ECONOMIA E SOCIOLOGIA RURAL, 10, 2004. Cuiabá, MT. Anais... Cuiabá: SOBER 1 CD ROM. 
SINDICATO NACIONAL DA INDÚSTRIA DE PRODUTOS PARA DEFESA AGRÍCOLA. SINDAG. Vendas de defensivos agrícolas por culturas de destinação e classes. Disponível em: <www.sindag.com.br>. Acesso em: 14 jan. 2008.

STEVENS, C. Harmonization, trade and the environment. International Environmental Affairs, Chicago, v.5, n.1, p. 42-49, Win. 1993.

TOBEY, J. The Effects of Domestic Environmental Policies on Patterns of World trade: an Empirical Test. Kyklos, Zurich, v.43, n.2, p.191-209, Apr. 1990.

TOBEY, J. Effects of Domestic Environmental Policy on Patterns of International Trade. In: SHANE, M. D. AND H. VAN WITZKE (Ed.). The Environment, Government Policies, and International Trade: A Proceedings. USDA: Staff Report No. AGES 9314. 1993.

U.S. DEPARTMENT OF AGRICULTURE. USDA. Economic Research Service. Estimates of Producer and Consumer Subsidy Equivalents: Government Intervention in Agriculture, 1982-92." SB-913 Washington, DC, Dec. 1994.

WALTER, I. The Pollution Content of American Trade. Economic Inquiry, Huntington Beach, v. 11, n. 6, p. 61-70, Mar. 1973. 